\title{
IMMUNOMODULATION OF EXPERIMENTAL AUTOIMMUNE UVEORETINITIS: A MODEL OF TOLERANCE INDUCTION WITH RETINAL ANTIGENS
}

\author{
A. D. DICK, Y. F. CHENG, J. LIVERSIDGE and J. V. FORRESTER \\ Aberdeen
}

\begin{abstract}
SUMMARY
Experimental autoimmune uveoretinitis (EAU) is a CD4+ T-lymphocyte mediated inflammation of the uveal tract and retina. As a model of human posterior uveitis it permits further understanding of the underlying immunopathogenesis of uveitis. It also allows for preclinical trials of immunosuppressive therapies and in vivo assessment of alternative strategies for immunointervention. This review highlights possible immunostrategic modalities which prevent the initiation or perpetuation of the immune response, and in particular reports on the novel effect of intranasal induction of tolerance with retinal antigens, prior to immunisation with retinal antigens. The mechanisms and potential application of this 'natural' method of immunosuppression in the treatment of autoimmune disease are discussed.
\end{abstract}

Posterior uveitis presents as a spectrum of chronic intraocular inflammatory conditions which have clinical features in common, including retinal vasculitis, focal chorioretinal infiltrates and vitritis. ${ }^{1-3}$ Experimental autoimmune uveoretinitis (EAU) provides a useful model for human posterior uveitis since many of the clinical signs can be mimicked closely. The treatment of chronic intraocular inflammatory conditions in man is at present relatively non-specific and control of the underlying inflammatory response with steroids and cyclosporin $\mathrm{A}^{4-6}$ may be limited in practice by the development of drug resistance and drug toxicity. Cyclosporin acts by inhibiting IL2-R expression on activated lymphocytes, suppressing the T-cell response. ${ }^{7}$ The newer immunosuppressants FK 506 and rapamycin, which are currently under investigation both clinically and experimentally, ${ }^{8.9}$ although effective at much lower doses are likely to encounter problems similar to those of cyclosporin.

Correspondence to: Dr A. D. Dick, BSc, MD, MRCP, FRCS, FRCOphth, Department of Ophthalmology, Medical School, Foresterhill, Aberdeen AB9 2ZD, UK.

\section{MODELS OF HUMAN POSTERIOR UVEORETINITIS}

EAU can be induced in various animal species by immunisation with retinal antigens and adjuvants. The common retinal antigens studied include $\mathrm{S}$-antigen $(\mathrm{S}-\mathrm{Ag})$ and interphotoreceptor retinol binding protein (IRBP), both of which are highly uveitogenic ${ }^{10,11}$ and have had their amino acid sequences and epitope profiles established with reference to the uveitogenic nature of these peptide fragments. ${ }^{12.13}$ To date, however, it is still unknown which of these antigens or which, if any, epitope of the protein is the dominant uveitogen (antigen) in vivo. Several other antigens have also been found to be uveitogenic in the animal model, and these include opsin, ${ }^{14}$ retinal pigment epithelial proteins ${ }^{15.16}$ and phosducin. ${ }^{17}$ By varying the species, dose of antigen and adjuvant employed within the immunising protocol different forms of uveitis can be produced, reflecting the spectrum of posterior uveitis seen in man. ${ }^{1,2.18 .19}$ The most frequently investigated model of EAU has been S-Ag induced EAU in Lewis rats, because this model provides a reproducible severe disease with a clear end-point, and can thus be modified and monitored by various alternative immunotherapies and immunological probes. IRBP also produces an acute EAU in Lewis rats with histological features similar to those of S-Ag induced EAU. ${ }^{20}$ Both antigens, during the acute stages of the disease, give rise to a retinal vasculitis and vitritis. The retinal vasculitis is particularly severe when pertussis toxin is used along with complete Freund's adjuvant (CFA). The inflammatory response consists of both polymorphonuclear and mononuclear cells which infiltrate the ciliary body, choroid and both neural and photoreceptor layers of the retina. ${ }^{14}$ Once the acute inflammatory response has subsided, mononuclear cells infiltrate the choroid and form granulomas, at which time destruction of the rod photoreceptor outer segments is apparent. ${ }^{2.14}$ During active inflammation in Lewis rats, S-Ag-specific T-cells migrate into the eye ${ }^{21}$ as part of a larger influx of 
CD4+ T-lýmphocytes within the early choroidal infiltrate. ${ }^{22}$ Antigen-specific CD4+ T-cells can induce disease when adoptively transferred, supporting the evidence that EAU is a CD4+ T-cell mediated autoimmune response. ${ }^{23}$

There are many problems, however, when comparing the animal model with human posterior uveoretinitis, one of which is that the inflammatory response is induced by 'external' administration of the antigen in combination with adjuvant (immunisation). In order to establish both consistent and reliable responses in the animal model, many investigators have, in addition to CFA, used pertussis toxin as an accessory adjuvant. The susceptibility of animals to develop EAU after inoculations with retinal antigens also depends upon the genetic constitution of the animals. $^{24,25}$ The use of pertussis can overcome these genetic differences. ${ }^{26}$ Controversy over the use of pertussis is further highlighted by the finding that it is difficult to induce mucosal tolerance after pretreatment with pertussis in rats $^{27}$ and also that pertussis modulates both vascular permeability $^{28}$ and T-cell function ${ }^{29}$ and inhibits the induction of antigen-induced peripheral T-cell tolerance in experimental allergic encephalomyelitis (EAE) in mice. ${ }^{30}$

In an attempt to overcome the complexity of multiple putative retinal autoantigens in EAU and additional exogenous factors (for example the use of pertussis toxin, which induces pronounced lymphocytosis, acts as a T-cell mitogen and increases immunoglobulin $E$ responses), we have studied a model of EAU induced by a heterologous mixture of retinal antigens: retinal extract (RE). The inflammatory response was monitored by both a clinical and customised histological grading system (Table I). ${ }^{31}$ Because most previous studies of immunomodulation of EAU in Lewis rats have depended upon the acute or hyperacute model, it has been difficult to evaluate, by histologi-

Table I. Customised histopathological grading of experimental autoimmune uveoretinitis

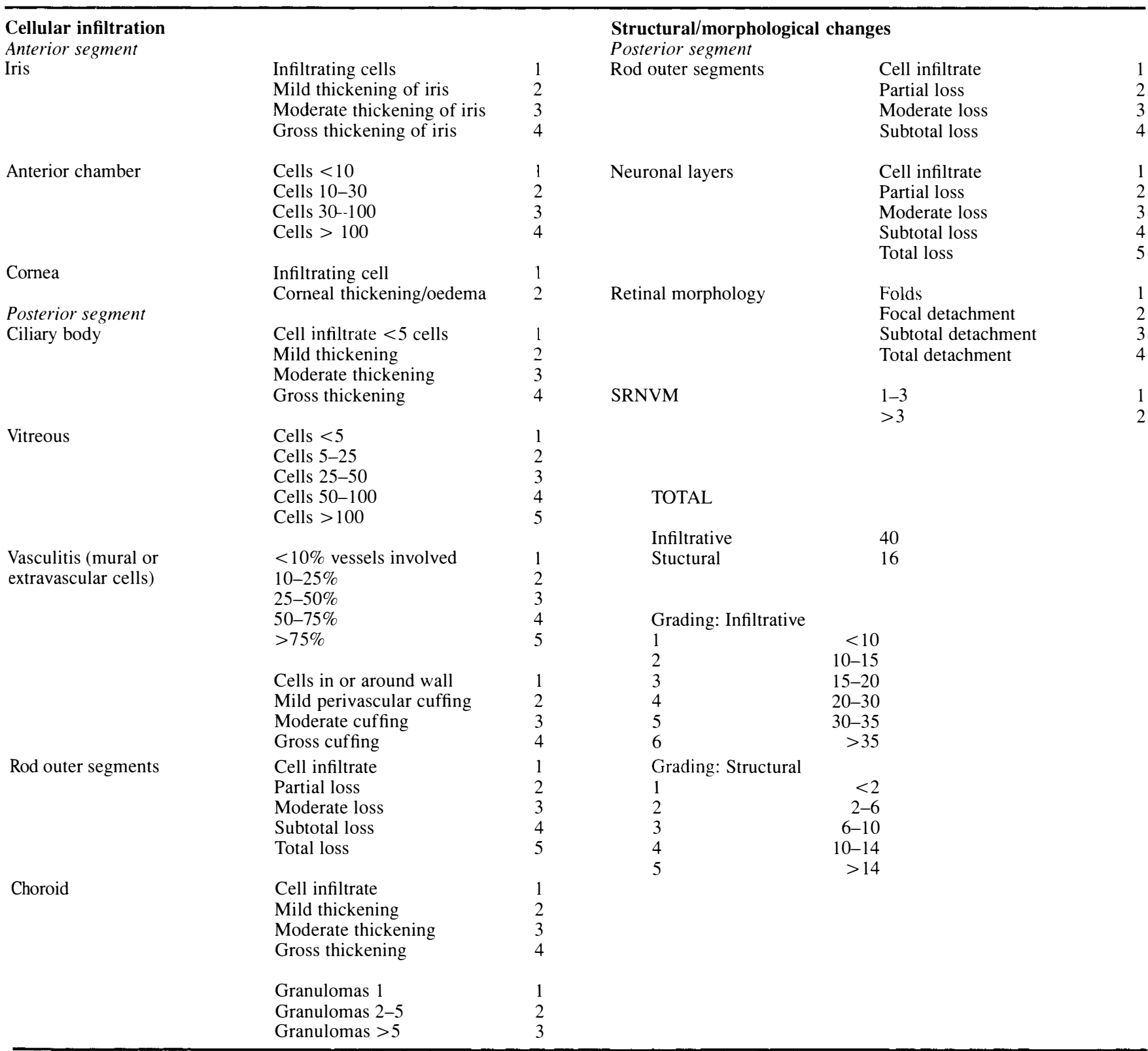

SRNVM, subretinal neovascular membrane. 

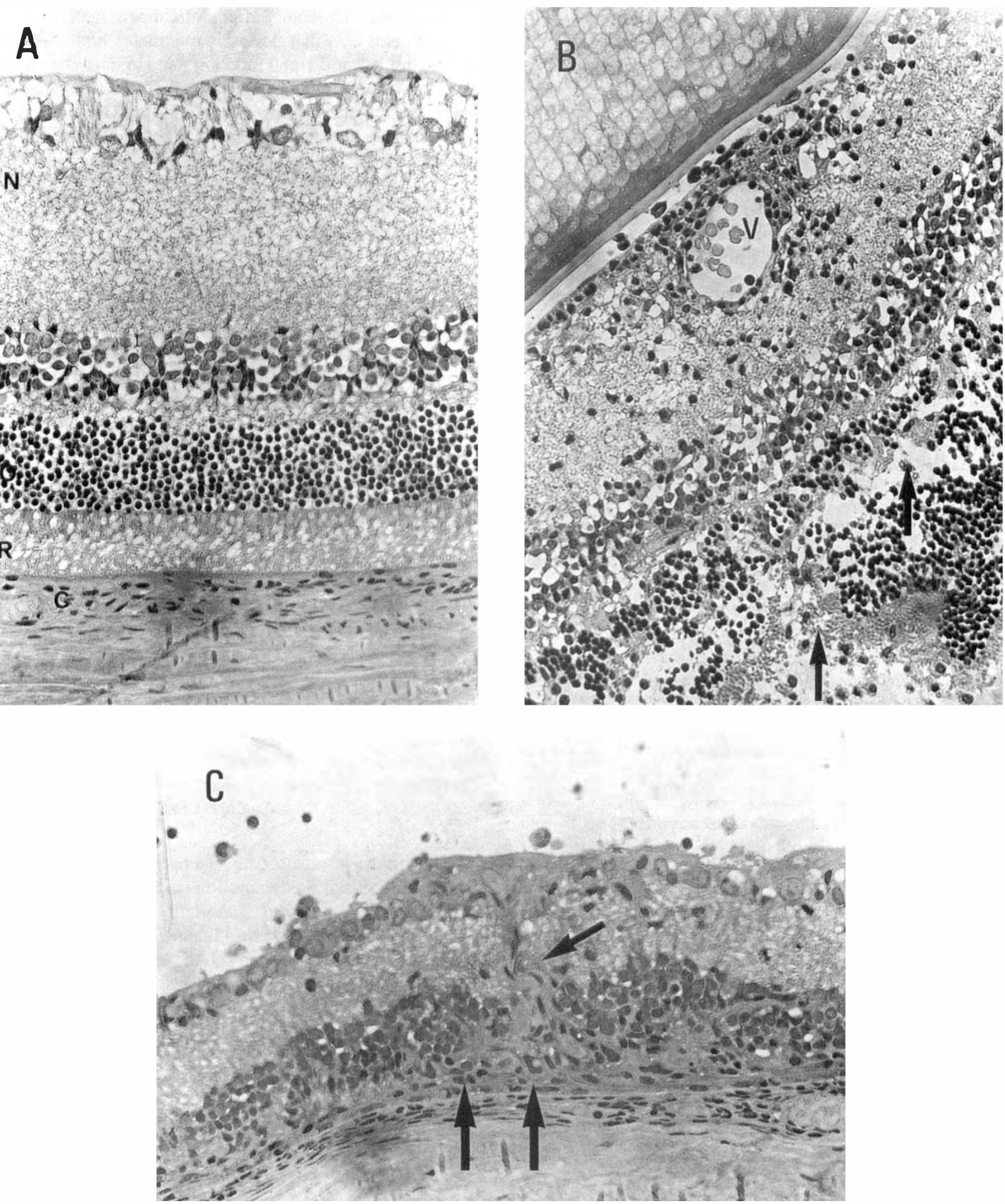

Fig. 1. Histological appearance of retinal extract $(R E)$-induced experimental autoimmune uveoretinitis (EAU). (A) Normal Lewis rat retina. $N$, nerve fibre layer; $O$, outer nuclear layer $R$, rod outer segments (ROS); $C$, choroid. (B) Active EAU: day 12 post-immunisation with $1000 \mu \mathrm{g} R E$. During the active infiltrative stages of EAU there is evidence of vasculitis $(V)$ and inflammatory cell infiltrate with loss of ROS and necrosis of outer nuclearlayer (arrows). (C) Chronic morphological changes in EAU, day 21 post-immunisiation with $640 \mu \mathrm{g}$ of $R E$. Note the reduced amount of inflammatory cell infiltrate within the retina compared with $(B)$. The main features are total loss of ROS (two arrows) and development of fibrovascular new growth (single arrow). 

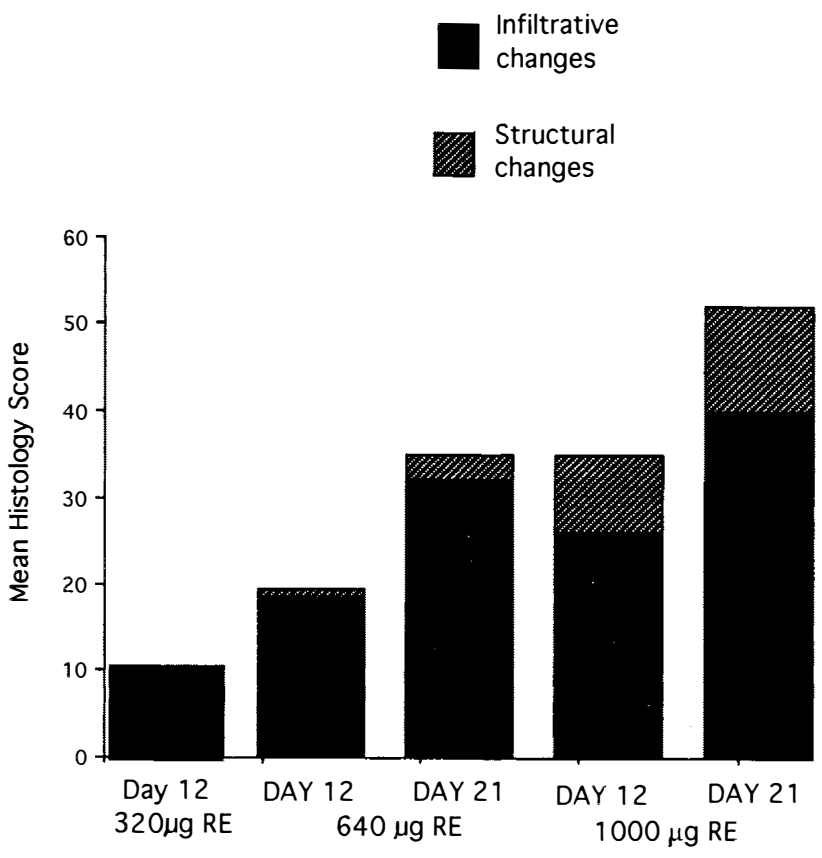

Immunising dose of RE

Fig. 2. Histopathological changes in RE-induced EAU

cal means, what is essentially an all or none phenomenon. Accordingly, studies of different immunointerventional strategies have used, as the end-point, the day of clinical response as observed by slit lamp biomicroscopy. 'Effective' immunosuppression is taken as a delay in the day of onset. The use of the histological grading system permits a semiquantitative assessment of both severity and extent of infiltrative and structural/morphological changes of the uveoretina throughout the time course of the inflammatory response in EAU (Figs. 1, 2).

\section{IMMUNOMODULATION OF EAU}

Attempts to minimise the inflammatory response in EAU may be targeted at various stages of the immune response after the initial immunisation with retinal antigen. Presentation of antigen by professional antigen presenting cells (APC) to autoreactive T-cells is dependent upon recognising the immune peptide in association with $\mathrm{MHC}$ antigens. CD4+ T-lymphocytes are predominantly stimulated by peptide recognition in association with MHC class II antigens, together with essential co-stimulatory accessory molecule interactions. Prevention of antigen presentation can be achieved with monoclonal antibodies directed against components of TCR/peptide/MHC complex or against accessory molecules, for example intercellular adhesion molecule-1 (ICAM-1). Monoclonal antibodies to S-Ag have also been used successfully, probably via the generation of anti-idiotypes which inhibit induction of the disease. ${ }^{32,35}$ The concept of peptide blocking therapy has been successfully employed in other models of autoimmune disease, for example EAE,$^{36}$ but this approach in EAU is limited by the presence of multiple uveitogenic proteins and uveitogenic epitopes on each molecule, which we have previously alluded to. Approaches preven- ting antigen presentation in EAU, including antibodies directed against MHC class II antigens ${ }^{37}$ or the CD4 antigen, ${ }^{38}$ have been successful. However, although at first sight this mechanism appears attractive, it may be limited in practice by its relative lack of specificity, and potentially short-term approach in targeting CD4+ T-lymphocytes. Resistance due to anti-idiotypic or anti-immunoglobulin responses to the therapeutic antibody also limits long-term treatment.

Once the autoreactive T-cell is activated it then makes its way to the target organ where adhesion of T-cells to the retinal microvascular endothelial cells occurs. This may be a random migration of cells although 'homing' molecules on endothelial cells have been proposed. ${ }^{39}$ The endothelial cells become activated, as demonstrated by electron microscopy prior to the clinical onset of the disease $^{40.41}$ and both endothelial cells and retinal pigment epithelial cells express adhesion molecules, for example ICAM-I ${ }^{42}$ ) and intergrins. It has also been shown that antibodies directed against these molecules inhibit adhesion of CD4+ T-cells to monolayers of these cells in vitro. ${ }^{43}$ One of the newer clinical immunosuppressives, FK 506, has been shown to act, at least in part, at this level ${ }^{44}$ by downregulating ICAM-1 expression.

Inhibiting the immune response can be achieved by preventing the effector cell response. We have previously mentioned that EAU is mediated by CD4+ T-cells. ${ }^{23} \mathrm{As}$ specific autoreactive T-cells are generated, amplification and modulation of the immune response occurs through release of cytokines, which can be both inhibitory or augmentory. Indeed, subsets of CD4+ T-cells have been further classified by the cytokines they secrete, ${ }^{45}$ where different CD4+ subsets generate or inhibit a delayed hypersensitivity response. Modulation of the effector response can be attained by directing antibodies against such activating cytokines, for example interleukin-2 (IL-2), ${ }^{46}$ or against adhesion molecules as previously mentioned. Other methods of inhibiting the effector cell response include generating suppressor cells or cytokines. Anterior chamber associated immune deviation (ACAID) is a phenomenon where an altered immune response to antigen directly placed in the anterior chamber is generated. ${ }^{47}$ Intracameral injection of antigens generates ocular cytokines, in particular transforming growth factor (TGF- $\beta$ ), a small secreted polypeptide which has suppressive actions on T-cell activation. ${ }^{48}$ The use of such lymphokines to suppress EAU has recently been reported. ${ }^{49}$

Tolerance is a state of immunological unresponsiveness, and in the adult is maintained by either the generation of suppressor T-cells or anergising the CD4+ T-cell response. Various methods exist to induce a state of tolerance or suppression in the adult, some inherently more artificial than others. Intravenous administration of syngeneic antigen-coupled splenocytes induces a state of tolerance to subsequent immunisation with antigen in animal models of autoimmune disease, ${ }^{50}$ which is thought to be mediated by T-cell anergy because of the lack of costimulatory factors at the time of antigen presentation. ${ }^{51}$ 
The human immune system receives most of its external stimuli at mucosal surfaces: from food and bacteria, particularly in the gastrointestinal tract, and from airborne antigenic material in the mucosa of the respiratory tract. The vast majority of the exogenous insults are non-pathogenic. The immunological effect of 'ingestion' of foreign proteins by these routes tends towards a state of immunological tolerance. ${ }^{52-54}$ Oral feeding of milligram doses of antigen prior to immunisation with antigen has been shown to modify both EAU ${ }^{55,56}$ and EAE. ${ }^{57}$ In these models the suppression of the effector cell response is both antigen- and disease-specific. Recently, we have reported the successful suppression of EAU by intranasal feeding of microgram quantities of antigen prior to immunisation with RE. ${ }^{31}$

In man, trials are in progress of several methods of immunomodulation. Daily oral doses of milligram quantities of immunogenic proteins are being administered to patients with multiple sclerosis and posterior uveitis. Recently, a preliminary report commented on the beneficial effect of feeding specific bovine myelin neuropeptides to patients with multiple sclerosis. ${ }^{58}$ In other autoimmune diseases, for example rheumatoid arthritis, trials are also in progress to assess the effect of anti-CD4+ antibody treatment and anti-TNF (tumour necrosis factor) therapy in the control of the autoimmune inflammatory response. Development of other specific targeted antibody therapies against antigen, cytokines or specific cellular markers of activation may in future yield greater benefits, particularly with the development of phage banks and specific humanised antibodies. Also the development of synthetic or recombinant cytokines known to suppress the inflammatory response, for example TGF- $\beta$, may also be used as adjunctive immunotherapy. Tolerance therapy, however, has the advantage of utilising a natural phenomenon, inducing a powerful method of immunosuppression.

\section{MUCOSAL TOLERANCE INDUCTION IN EAU}

We have studied the immunosuppressive effect of intranasal inoculation of microgram quantities of a highly uveitogenic mixture of retinal antigens, RE, on REinduced EAU, prior to and after immunisation with RE. Within these groups of experiments EAU was induced with RE and CFA but without the addition of pertussis toxin so as to avoid any potential effect on vascular permeability and suppressor T-cell function. Table II summarises both the clinical and histological response in both control animals who were nasally inoculated with phosphate-buffered saline (PBS) and RE-tolerised animals. Overall, we demonstrated a profound suppression of both clinical and histological features of EAU by the induction of tolerance through intranasal inoculation with RE, and have previously reported the features of this histological suppression. ${ }^{31}$ Tolerance induced by this route appears to be antigen-specific, as we also demonstrated that inhalation of S-Ag protects only against subsequent challenge with $\mathrm{S}-\mathrm{Ag}$ and not other autoantigens present in RE, whereas inhalation of RE will not surprisingly protect against $\mathrm{S}-\mathrm{Ag}$ induced EAU. These findings are contrary to those of Weiner et al. ${ }^{58}$ who proposed that oral feeding of specific antigens generates a suppressor state against all neuroantigens in multiple sclerosis. We have also attempted to determine whether tolerance therapy during both the preclinical phase and during active clinical inflammation will suppress the inflammatory response. Modulation of the continuing immune response by mucosal tolerance induction ${ }^{59}$ has previously been shown to be successful in other models of autoimmune disease, for example EAE. However, this model of EAE is both chronic and relapsing in nature, unlike the model of REinduced EAU. Table III documents our findings of the clinical and histological responses in rats treated with

Table II. Clinical and histological response in controls and retinal antigen tolerised rats

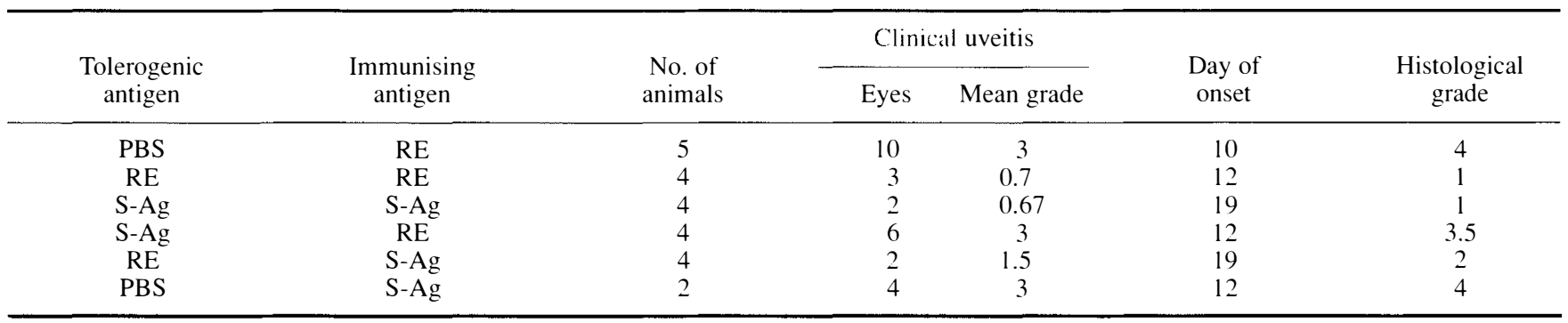

PBS, phosphate-buffered saline; RE, retinal extract; S-Ag. S-antigen.

Table III. Clinical and histological responses in rats treated with intranasal administration of retinal extract (RE) at various intervals post-immunisation

\begin{tabular}{cccccc}
\hline $\begin{array}{c}\text { Immunised/RE } \\
(\text { day } 0)\end{array}$ & $\begin{array}{c}\text { Tolerised } \\
\text { RE }\end{array}$ & $\begin{array}{c}\text { Incidence } \\
\text { (eyes) }\end{array}$ & $\begin{array}{c}\text { Day of } \\
\text { onset }\end{array}$ & $\begin{array}{c}\text { Mean clinical } \\
\text { severity }\end{array}$ & $\begin{array}{c}\text { Histological grade } \\
\text { (day 18) }\end{array}$ \\
\hline $\begin{array}{c}\text { Group A } \\
(n=4) \\
\begin{array}{c}\text { Group B } \\
(n=4)\end{array}\end{array}$ & Days 0-5, 8-12 & $6 / 8$ & 10 & 0.75 & 2 \\
$\begin{array}{c}\text { Group C } \\
(n=4)\end{array}$ & Days 10-18 & $6 / 8$ & 10 & 0.88 & 2 \\
\hline
\end{tabular}




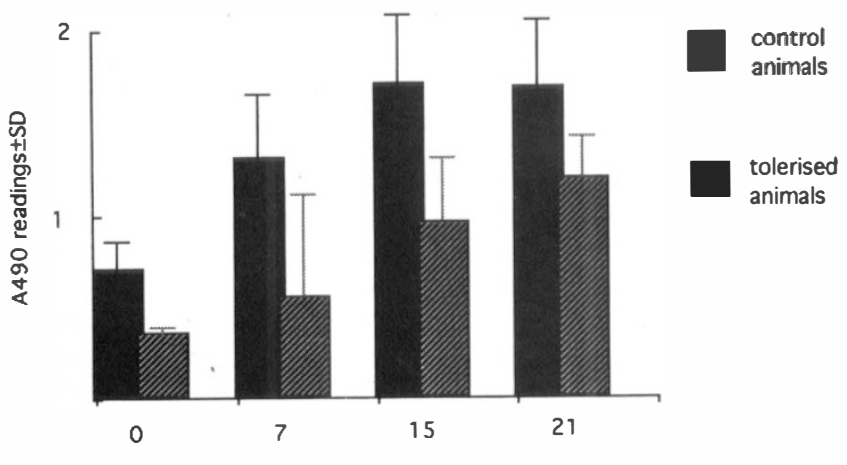

DAYS POST-IMMUNISATION

Fig. 3. Anti-RE antibody activity (ELISA) in RE-induced EAU in controls and RE-tolerised rats.

intranasal administration of RE at various intervals after immunisation with RE. The incidence of EAU in animals that had received RE was not reduced, but there was a suppression of both the clinical and to a lesser degree the histological features of EAU. Within each test group there was one animal which still demonstrated profound intraocular inflammation equivalent to that in the control animals. The inconsistent suppression which we obtained in our experiments may be explained by recent data ${ }^{60}$ which suggest that although the tolerogenic signal might be dominant in the immune response, once activated, T-cells cannot be silenced. In our model sensitised lymphoctyes may become increasingly resistant to being tolerised when compared with our earlier studies with naive T-cells. A further problem with tolerance therapy in sensitised animals may result from the antigen handling at the mucosal surface, that is the processing and presentation of the native proteins by professional APC, for example dendritic cells in respiratory mucosa. ${ }^{61}$ The processing of antigen is an important influence on the specificity of immune responses. Alteration of protein structures by the intracellular processing mechanisms, at sites distant from pathogenic loci, may in turn affect T-cell clonal specificity, ${ }^{62}$ particularly when attempting modulation of the immune response in the presence of sensitised T-cells. The epitopes generated by processing of a particular antigen may differ depending upon the type of APC or the method of antigen capture. ${ }^{63}$

Mucosal tolerance, in particular oral tolerance, is thought to be mediated by generation of specific CD8+ T-lymphocytes. ${ }^{52-56}$ In our model of nasal tolerance, suppression of the clinical and histological response is accompanied by antigen-specific suppression of delayed hypersensitivity reactivity (DTH). Table IV documents the results of ear lobe DTH responses in both control animals and tolerised animals 12 days after immunisation with RE. There was a significant reduction in reactivity to $\mathrm{RE}$ in the tolerised animals, which also generated a DTH response to a non-specific antigen (PPD) present in CFA but not RE, that was equivalent to the response in the control group of animals. Tolerised animals also mount a normal humoral response to RE, which rises over 3 weeks after immunisation and was not statistically different from that in control animals (Fig. 3). The presence of an active antibody response in association with a reduced DTH response would be consistent with either an active suppression of effector cells through, for example, the generation of specific CD8+ T-lymphocytes or by T-cells anergy. Recent preliminary findings demonstrate that tolerance can be transferred by tolerised T-cells, which would support the presence of a de novo specific suppressor cell (data not shown). Bystander suppression is unlikely as animals were able to mount a DTH response to PPD. Which suppressor cell is generated by mucosal tolerance induction remains unknown. $\mathrm{CD} 8+$ cells, which have been proposed, can recognise antigen but are MHC class I restricted, not normally recognised as part of antigen presentation in the respiratory mucosa. The autoimmune response is usually generated through MHC class II antigens and CD4+ T-cells, and the dendritic cells of the respiratory mucosa are known to actively express MHC class II antigen. ${ }^{61}$ Both CD4+ and CD8+ T-cells can be further subdivided functionally by the cytokines they secrete. ${ }^{64.65}$ Investigation into the cytokine secretion of tolerised splenoctyes will help further differentiate the phenotype of CD4+ and CD8+ T-cells present in tolerised animals and elucidate the mechanism of suppression. A switch from Th1 to Th2 cell activity would also explain a reduction of DTH with sparing of humoral responses. Tolerisation may induce T-cells which secrete a cytokine profile towards Th2 (IL-4, IL-5, IL-10), suppressing DTH responses and enhancing B-cell responses and immunoglobulin $\mathrm{G}$ production. ${ }^{66}$

The potential application of this form of natural immunosuppression has yet to be fully elucidated, but both intranasal and oral tolerance therapy have potential as a future clinical therapy for autoimmune disease. The more traditional methods of enhancing or re-establishing a state of tolerance or suppression in EAU have focused on the parenteral administration of antigens. The administration of antigens via the nasal and oral mucosal route,

Table IV. Delayed hypersensitivity reactivity (DTH) responses in controls and re-tolerised rats

\begin{tabular}{cccccc}
\hline Group & Tolerised & Immunised & $\begin{array}{c}\text { Ear } \\
\text { tested for }\end{array}$ & $\begin{array}{c}\text { Disease } \\
\text { frequency }\end{array}$ & $\begin{array}{c}\text { Increase in } \\
\text { ear thickness (mm) }\end{array}$ \\
\hline A & + & RE & RE & $2 / 6$ & $0.4 \pm 0.08$ \\
B & + & RE & PPD & $0 / 6$ & $0.43 \pm 0.32$ \\
C & - & RE & PPD & $6 / 6$ & $0.9 \pm 0.37$ \\
D & - & RE & RE & $4 / 6$ & $0.46 \pm 0.23$ \\
E & - & CFA & PPD & $0 / 6$ & $0.03 \pm 0.047$ \\
F & - & CFA & & $0.23 \pm 0.2$ \\
\hline
\end{tabular}

RE, retinal extract; CFA, complete Freund's adjuvant; PPD, purified protein derivative. 
particularly with tolerogenic and non-autoimmunogenic chemically modified forms, would exploit a natural and powerful phenomenon of tolerance induction and immunosuppression, and offers a novel approach to specific immune targeted therapy in autoimmune disease. Although an attractive therapeutic strategy, it is important to establish that tolerance therapy does not exacerbate the disease in sensitised individuals or during disease relapse. One practical limitation at present is that neither oral nor intranasal tolerance induction appears to suppress active disease consistently and significantly, but this may be because the animal model is not chronic.

The immunotherapeutic approaches outlined in this paper all have difficulties. For example, the generation of peptide blocking therapy will not become possible until uveitogenic peptides for each patient can be detected. Directing monoclonal antibodies against MHC class I or II antigens of CP!+cells is likely to be non-specific and may produce more harm than good. The most likely imminent therapies will be those which are targeted against the cytokine network, for example interferon- $\gamma$ and IL-2. Future understanding of the underlying mechanisms behind tolerance induction will help develop the possibilities of such therapies. It may be that we have to develop multifaceted approaches to therapy to overcome the problems of multiple autoantigens (which also may be present in various amounts in each individual) and thus be able to initially suppress active disease and, importantly, maintain disease remission.

This work was supported by grants from the Grampian Health Board, Wellcome Trust and Scottish Home and Health Department. We would also like to thank Mr A. McKinnon for his assistance with the histological preparations.

Key words: Experimental autoimmune uveoretinitis (EAU), Immunomodulation, Intranasal tolerance, Tolerance, Uveoretinitis.

\section{REFERENCES}

1. Forrester JV. Endogenous posterior uveitis. Br J Ophthalmol 1990;74:620-3.

2. Forrester JV, Liversidge J, Dua HS, Towler H, McMenamin PG. Comparison of clinical and experimental uveitis. Curr Eye Res 1990;9:75-84.

3. Forrester JV. Uveitis: pathogenesis. Lancet 1991;388: $1489-501$.

4. Towler HM, Cliffe AM, Whiting P, Forrester JV. Low dose cyclosporin A and steroid therapy. Eye 1989;3:282-7.

5. Towler HM, Whiting PH, Forrester JV. Combination of low dose CsA and steroid therapy in chronic intraocular inflammation. Eye 1990;4:514-20.

6. Towler HM, Lightman SL, Forrester JV. Low dose CsA therapy of ocular inflammation: preliminary report of a long term follow up study. Autoimmunity 1992;5:259-64.

7. Granelli-Piperna A. In situ hybridisation for interleukin 2 receptor mRNA in T-cells activated in the presence or absence of CsA. J Exp Med 1988;5:1649-58.

8. Kawashima M, Mochizuki M. Effects of a new immunosuppressive agent FK 506 on the efferent limb of the immune response. Exp Eye Res 1990;51:565-72.

9. Mochizuki M, Iheda A, Shira O, Jukito S, Yoshimura K, Shimada N. Preclinical and clinical study of FK 506 in uveitis. Curr Eye Res 1992;11:87-97.

10. deKozak Y, Sakai J, Thillaye B, Faure JP. S-Ag induced experimental autoimmune uveoretinitis in rats. Curr Eye Res 1981;1:327-40.

11. Fox GM, Kuwabara T, Wiggert B, Redmond TM, Hess HH, Chader GJ, Gery I. EAU induced by IRBP: difference between EAU induced by IRBP and S-Ag. Clin Immunol Immunopathol 1987;43:256-64.

12. Si SJ, Borst DE, Redmond TM, Nickerson JM. Cloning of cDNA encoding human IRBP and comparison with bovine IRBP sequences. Gene 1989;80:99-109.

13. Shinohara T, Dietachold B, Donoso LA, Howitz J, Tao R. A primary and secondary structure of bovine retinal S-Ag (48 Kd protein). Proc Natl Acad Sci USA 1987;84:6975-9.

14. Gery I, Mochizuki M, Nussenblatt R. Retinal specific antigens and the immunopathogenic process they provoke. Prog Retinal Res 1986;5:75-109.

15. Broekhuyse RM, Kulhman ED, Winkens NJ, Van Vogt AHM. Experimental allergic anterior uveitis: a new form of experimental uveitis. Induction by a detergent-insoluble intrinsic protein fraction of the retinal pigment epithelium. Exp Eye Res 1991;52:465-74.

16. Broekhuyse RM, Kulhman ED, Winkens HJ. Experimental allergic posterior uveitis accompanied by epithelial cell accumulations (EAPU): a new type of experimental ocular disease induced by immunisation with PEP-65, a pigment epithelial polypeptide preparation. Exp Eye Res 1992;55: 819-26.

17. Dua HS, Lee RH, Lolley RN, Barrett JA, Abrams M, Forrester JV, Donoso LA. Induction of experimental autoimmune uveitis by the retinal photoreceptor cell protein, phosducin. Curr Eye Res 1992;11:107-12.

18. Faure JP. Autoimmunity and the retina. Curr Eye Res 1980; 2:215-301

19. Forrester JV, Borthwick GM, McMenamin PG. Ultrastructural pathology of S-Ag uveoretinitis. Invest Ophthalmol Vis Sci 1985;26:1281-92.

20. Harper FH, Liversidge J, Thompson AW, Forrester JV. Interphotoreceptor retinal binding protein induced EAU: an immunophenotypic analysis using alkaline phosphatase anti-alkaline phosphatase staining, dual immunofluorescence and confocal microscopy. Curr Eye Res 1992;11: $129-34$

21. Lightman SL, Yuen L. Relationship of blood retinal barrier breakdown to lymphocytic infiltration in EAU. Invest Ophthalmol Vis Sci 1990;31:511-9.

22. Liversidge J, Forrester JV. Experimental autoimmune uveoretinitis: immunophenotypic analysis of inflammatory cells in chorioretinal lesions. Curr Eye Res 1988;7:1231-41.

23. Caspi RR, Roberge FG, McAllister CG, El-Said M, Kuwabara T, Gery I, et al. T cell lines mediating experimental autoimmune uveoretinitis (EAU) in the rat. J Immunol 1986; 136:928-33.

24. Nussenblatt RB, Cevario SJ, Gery I. Altered suppressor cell activity in uveitis. Lancet 1980;2:722.

25. Nussenblatt RB. Experimental autoimmune uveoretinitis: mechanisms of disease and clinical therapeutic indications. Invest Ophthalmol Vis Sci 1991;32:3131-40.

26. Hirose S, Oasawara K, Natori T, Sasamoto Y, Ohno S, Matsuda H, Onoe K (1991) Regulation of experimental autoimmune uveitis in rats: separation of MHC and non-MHC gene effects. Clin Exp Immunol 1991;86:419-25.

27. Holt PG, McMenamin C. Defence against allergic sensitisation in the healthy lung: the role of inhalational tolerance. Clin Exp Allergy 1989;19:255-62.

28. Linthicum DS, Munoz JJ, Blassett A. Acute EAE in mice: adjuvant action of Bordetella pertussis is due to vasoactive amine sensitisation and increased permeability of the CNS. Cell Immunol 1982;73:299.

29. Hiroshima M, Yodoi J, Ishizaka K. Formation of IgE binding factors by rat T-lymphocytes: mechanisms of selective formation of IgE potentiating factors by treatment with Bordetella pertussis vaccine. J Immunol 1981;127:1804-9. 
30. Kamranđt T, Soloway PD, Perkins DL, Gefter ML. Pertussis toxin prevents the induction of peripheral T-cell anergy and enhances T-cell response to an encephalogenic peptide of myelin basic protein. J Immunol 1991;147:3296-302.

31. Dick AD, Cheng YF, McKinnon A, Liversidge J, Forrester JV. Nasal administration of retinal antigens suppresses the inflammatory response in experimental autoimmune uveoretinitis: a preliminary report of intranasal induction of tolerance with retinal antigens. Br J Ophthalmol 1993;77:171-5.

32. Dua HS, Sewell H, Forrester JV. The effect of retinal S-Ag specific monoclonal antibody therapy on experimental autoimmune uveoretinitis and experimental autoimmune pinealitis. Clin Exp Immunol 1989;75:100-5.

33. Dua HS, Liversidge J, Forrester JV. Immunomodulation of experimental autoimmune uveitis using a rat anti-retinal $\mathrm{S}$-antigen specific monoclonal antibody: evidence for a species difference. Eye 1989;3:69-78.

34. DeKozak Y, Mirshahi M, Boucheix C, Faure JP, Letts LG, Rothlein R. Prevention of experimental autoimmune uveoretinitis by active immunisation with autoantigen-specific monoclonal antibodies. Eur J Immunol 1990;17:541-7.

35. Dua HS, Abrams M, Barrett JA, Gregerson DS, Forrester JV, Donoso LA. Epitopes and idiotypes in experimental autoimmune uveoretinitis: a review. Curr Eye Res 1992;11: $59-66$.

36. Sakai K, Zamvill SS, Mitchell DJ, Hodgkinson S, Rothbard JB, Steinman L. Prevention of experimental allergic encephalomyelitis with peptides that block interaction of T-cells with major histocompatibility complex protein. Proc Natl Acad Sci USA 1989;86:9470-4.

37. Wetzig R, Hooks JJ, Percopo CM, Nussenblatt R, Chan CC, Detrick B. Anti-Ia antibody diminishes ocular inflammation in experimental autoimmune uveoretinitis. Curr Eye Res 1988;7:809-18.

38. Atalla L, Linker-Israeli M, Steinman L, Rao NA. Inhibition of autoimmune uveitis by anti CD4 antibody. Invest Ophthalmol Vis Sci 1990;31:7-11.

39. Picker LJ, Butcher EC. Physiological and molecular mechanisms of lymphocyte homing. Eur J Immunol 1992;10: 561-91.

40. Dua HS, McKinnon A, McMenamin PG, Forrester JV. Ultrastructural pathology of barrier sites in experimental autoimmune uveitis and experimental autoimmune pinealitis. Br J Ophthalmol 1991;75:391-7.

41. McMenamin PG, Forrester JV, Steptoe RJ, Dua HS. Ultrastructural pathology of experimental autoimmune uveitis: quantitative evidence of HEV-like changes in the retinal vascular endothelium. Lab Invest 1992;67:42-65.

42. Liversidge J, Forrester JV. Are accessory molecules implicated in activation of T-cells at the blood retinal barrier? Curr Eye Res 1990;9:131-9.

43. Liversidge J, Sewell H, Forrester JV. Interactions between lymphocytes and cells of the blood retinal barrier: mechanisms of T-lymphocyte adhesion to human capillary endothelial cells and retinal pigment epithelial cells in vitro. Immunology 1990;71:390-6.

44. Liversidge J, Thomson AWE, Forrester JV. FK 506 modulates accessory cell adhesion molecule expression and inhibits CD4 lymphocyte adhesion to retinal pigment epithelial cells in vivo: implications for therapy of uveoretinitis. Transplant Proc 1991;23:3339-405.

45. Powell D, McKnight AJ, Powrie F, Dycke R, Mason D. Subsets of CD4+ T cells and their roles in the induction and prevention of autoimmunity. Immunol Rev 1991;123:37-64.

46. Roberge FG, Lorberboum-Galski H, Le Hoange P, deSmet M, Chan CC, Fitzgerald D, Pastan I. Selective immunosuppression of activated T-cells with chimeric toxin IL2PE40: inhibition of experimental autoimmune uveoretinitis. J Immunol 1989;143:3498-502.

47. Kaplan HJ, Streilein JW. Immune response to immunisation via the anterior chamber of the eye. J Immunol 1977;118: 809-14.

48. Streilin JW, Wilbanks GA, Taylor A, Cousins S. Eye derived cytokines and the immunosuppressive intraocular microenvironment: a review. Curr Eye Res 1992;11:41-7.

49. Barton K, Hu XS, Zhao ZS, Calder VS, Lightman SL. Transforming Growth Factor-b as a therapeutic agent in ocular inflammation [abstract]. Congress of College of Ophthalmologists 1993 .

50. Dua HS, Gregerson DS, Donoso LA. Inhibition of experimental autoimmune uveitis by retinal photoreceptor antigens coupled to spleen cells. Cell Immunol 1992;139: 292-305.

51. Jenkins MC, Schwartz RH. Antigen presentation by chemically modified splenocytes induced antigen specific T-cell unresponsiveness in vitro and in vivo. J Exp Med 1987;165: 302-19.

52. Holt PG, Sedgwick J. Suppression of IgE responses following inhalation of antigens. Immunol Today 1987;8:14-5.

53. Mowat AM. The regulation of the immune responses to dietary protein antigens. Immunol Today 1987;8:93-5.

54. Stephen H, Thompson G, Staines NA. Could specific oral tolerance be a therapy to autoimmune disease? Immunol Today 1990;11:396-9.

55. Nussenblatt RB, Caspi RR, Mahdi R, Chan CC, Roberge F, Lider $\mathrm{O}$, et al. Inhibition of $\mathrm{S}-\mathrm{Ag}$ induced experimental autoimmune uveoretinitis by oral induction of tolerance with S-Ag. J Immunol 1990;144:1689-95.

56. Vrabec TR, Gregerson DS, Dua HS, Donoso LA. Inhibition of experimental autoimmune uveoretinitis by oral administration of S-Ag and synthetic peptides. Autoimmunity 1992; 12:175-84.

57. Lider O, Santos LMB, Lee CYS, Higgins PJ, Weiner HL. Suppression of EAE by oral administration of myelin basic protein: suppression of the disease, in vitro immune responses is mediated by $\mathrm{Ag}$-specific $\mathrm{CD} 8+\mathrm{T}$ cells. J Immunol 1988; 142:748-53.

58. Weiner HL, Mackin GA, Matsui M, Orav EJ, Khoury SJ, Dawson DM, Hafler DA. Double blind pilot trial of oral tolerance with myelin antigens in multiple sclerosis. Science 1993:259:1321-4.

59. Kennedy MK, Tan LJ, Dal Canto MC, Tuohy VK, Lu A, Trotter JL, Miller SD. Inhibition of murine relapsing experimental autoimmune encephalomyelitis by immune tolerance to proteolipid protein and its encephalogenic peptides. J Immunol 1990;144:905-15.

60. Friedman A, Malamed D. Relationship between tolerogenic and immunogenic signals in a T-lymphocyte immune response [abstract]. Proc Int Congress of Immunology 1992; 552.

61. Holt PG, Schon-Hegrad MA, Oliver J, Holt BJ, McMenamin PG. A contiguous network of dendritic antigen presenting cells within the respiratory epithelium. Int Arch Allergy Appl Immunol 1990;91:155-9.

62. Shastri N, Miller A, Sercarz EE. Amino acid residues distant from the determinant region can profoundly affect activation of T-cell clones by related antigens. J Immunol 1986; $136: 371-9$

63. Levine TP, Chain BM. The cell biology of antigen processing. Crit Rev Biochem Mol Biol 1991;26:439-73.

64. Mosmann TR, Coffman RL. Th1 and Th2 cells: different patterns of lymphokine secretion lead to different functional properties. Annu Rev Immunol 1989;7:145-51.

65. Bloom BR, Salgome P, Diamond B. Revisiting and revising suppressor T-cells. Immunol Today 1992;13:131-6.

66. Maggi E, Parranchi P, Mazetti R, et al. Reciprocal regulatory effects of IFN- $\gamma$ and IL- 4 on the in vitro development of human Th1 and Th2 clones. J Immunol 1992;148: 2142-7. 